\title{
CORRIGENDA
}

\section{EVALUATION OF EXPLICIT EXPRESSIONS FOR MEAN CHARACTERISTICS OF ATOMIC SPECTRA}

\author{
R. KARAZIJA \\ Institute of Theoretical Physics and Astronomy \\ 2600 Vilnius, Lithuania
}

(Acta Phys. Hung., 70, pp. 367-379, 1991)

The equation (28) for $N$ multiplier should read:

$$
\mathcal{N}=(-1)^{h+\sum_{i} t_{i}} \prod_{i}\left(\begin{array}{l}
\Omega_{i} \\
N_{i}
\end{array}\right)^{-1}\left(\begin{array}{c}
\Omega_{i}-p_{i} \\
N_{i}-t_{i}
\end{array}\right), \quad N_{i} \geq t_{i}
$$

where $h$ is the number of loops in the diagram. 